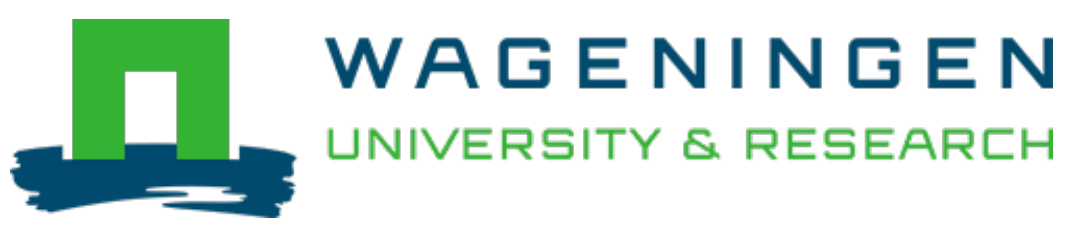

\title{
Effect of soaking and phytase treatment on phytic acid, calcium, iron and zinc in rice fractions
}

\author{
Food Chemistry \\ Liang, J.; Han, B.Z.; Nout, M.J.R.; Hamer, R.J. \\ https://doi.org/10.1016/j.foodchem.2008.12.051
}

This publication is made publicly available in the institutional repository of Wageningen University and Research, under the terms of article $25 \mathrm{fa}$ of the Dutch Copyright Act, also known as the Amendment Taverne. This has been done with explicit consent by the author.

Article 25 fa states that the author of a short scientific work funded either wholly or partially by Dutch public funds is entitled to make that work publicly available for no consideration following a reasonable period of time after the work was first published, provided that clear reference is made to the source of the first publication of the work.

This publication is distributed under The Association of Universities in the Netherlands (VSNU) 'Article $25 \mathrm{fa}$ implementation' project. In this project research outputs of researchers employed by Dutch Universities that comply with the legal requirements of Article $25 \mathrm{fa}$ of the Dutch Copyright Act are distributed online and free of cost or other barriers in institutional repositories. Research outputs are distributed six months after their first online publication in the original published version and with proper attribution to the source of the original publication.

You are permitted to download and use the publication for personal purposes. All rights remain with the author(s) and / or copyright owner(s) of this work. Any use of the publication or parts of it other than authorised under article $25 \mathrm{fa}$ of the Dutch Copyright act is prohibited. Wageningen University \& Research and the author(s) of this publication shall not be held responsible or liable for any damages resulting from your (re)use of this publication.

For questions regarding the public availability of this publication please contact openscience.library@wur.nl 


\title{
Effect of soaking and phytase treatment on phytic acid, calcium, iron and zinc in rice fractions
}

\author{
Jianfen Liang ${ }^{\mathrm{a}, \mathrm{b}}$, Bei-Zhong Han ${ }^{\mathrm{a}}$, M.J. Robert Nout ${ }^{\mathrm{b}, *}$, Robert J. Hamer ${ }^{\mathrm{c}}$ \\ a College of Food Science and Nutritional Engineering, China Agricultural University, Beijing 100083, PR China \\ ${ }^{\mathrm{b}}$ Laboratory of Food Microbiology, Wageningen University, P.O. Box 8129, 6700 EV Wageningen, The Netherlands \\ ${ }^{\mathrm{c}}$ Laboratory of Food Chemistry, Wageningen University, Wageningen, The Netherlands
}

\section{A R T I C L E I N F O}

\section{Article history:}

Received 4 July 2008

Received in revised form 11 December 2008

Accepted 15 December 2008

\section{Keywords:}

Soaking

Phytase

Minerals

Phytic acid

Rice

\begin{abstract}
A B S T R A C T
With the aim to maximise phytic acid removal and minimise losses of dry matter and minerals (Ca, Fe, $\mathrm{Zn}$ ) in rice, three products (whole kernels and flour milled from white and brown rice; and bran, all from the same batch of variety Kenjian 90-31) were soaked in demineralized water at $10^{\circ} \mathrm{C}(\mathrm{SDW}), \mathrm{NaAc}$ buffer of $\mathrm{pH} 3.5$ at $10{ }^{\circ} \mathrm{C}(\mathrm{SAB})$, and $500 \mathrm{U} \mathrm{L}^{-1}$ phytase of $\mathrm{pH} 5.5$ at $50{ }^{\circ} \mathrm{C}(\mathrm{SPS})$. In whole kernels and flour of white rice, phytic acid removal was $100 \%$ by all treatments; losses of dry matter, Ca, Fe, and $\mathrm{Zn}$ were $2-5 \%, 12-63 \%, 9-10 \%$, and apparent gain of $63-72 \%$, respectively. In whole brown rice, SAB removed $75 \%$ phytic acid, and SPS 100\% from flour; dry matter, Ca, Fe, and Zn losses were 1-16\%, 26-56\%, 39$45 \%$, and $23-24 \%$. In rice bran, SPS removed $92 \%$ phytic acid, and SAB $50 \%$; dry matter, Ca, Zn, and Fe losses were $20 \%, 48 \%, 63 \%$, and apparent gain of $5 \%$, respectively.
\end{abstract}

(c) 2008 Elsevier Ltd. All rights reserved.

\section{Introduction}

In China, rice plays an important role in human nutrition. In 2002 and 2003, the intake of rice and rice products represented $35 \%$ of the total energy intake (FAO, 2006; Wang, 2005). In addition to energy, rice also supplies important micronutrients, such as iron, zinc, calcium and some vitamins, especially in rural diets. In 2002, iron consumption in rural areas was estimated at $23.1 \mathrm{mg} /$ capita/day (Wang, 2005), of which about $8.5 \%$ was estimated to originate from rice and rice products. Poor mineral bioavailability is a major cause of mineral deficiencies. For example, it was reported that prevalence of iron deficiency related anaemia could be associated with poor iron bioavailability (Ma, 2007) caused by low intake and the occurrence of antinutritional factors such as phytic acid.

In order to increase the bioavailability of minerals in rice and rice products, rice varieties with higher mineral contents and lower levels of antinutritional factors (phytic acid, PA) could be selected for cultivation (Liang, Han, Han, Nout, \& Hamer, 2007), rice milling by dry abrasion could be optimised for maximum PA removal with minimum losses of minerals (Liang et al., 2008b), and wet processing of rice could be promoted to remove PA (Liang, Han, Nout, \& Hamer, 2008a). Although the first two approaches were shown to improve in vitro solubility of minerals, residual PA levels were still

\footnotetext{
* Corresponding author. Fax: +31 317484978.

E-mail address: rob.nout@wur.nl (M.J. Robert Nout).
}

too high to achieve adequate availability of minerals for nutrition. Studies on other cereals indicated that wet processing, such as soaking, germination and fermentation could effectively decrease PA and improve the bioavailability of minerals (Lestienne, IcardVernière, Mouquet, Picq, \& Trèche, 2005c).

Soaking is widely applied at both household and industrial scale. It is the most important operation in the process of rice noodle making (Lu, Li, Min, Wang, \& Tatsumi, 2005) to soften the kernel prior to pulping. During rice soaking for noodle making, a natural fermentative acidification takes place, and this is regarded as important for noodle quality. Previously, it was reported that soaking of other cereals such as pearl millet with endogenous or exogenous (i.e. added) phytase enzymes at optimum conditions increased the in vitro solubility of iron and zinc by $2-23 \%$ (Lestienne, Besançon, Caporiccio, Lullien-Pellerin, \& Trèche, 2005a; Lestienne, Caporiccio, Besançon, Rochette, \& Trèche, 2005b). In millet, dehulling and milling prior to soaking facilitated phytate degradation by endogenous phytases, whereas in contrast, soya beans had increased phytate levels after dehulling (Lestienne, Mouquet-Rivier, Icard-Vernière, Rochette, $\&$ Trèche, 2005d). Whilst it has been observed that soaking has the advantage of decreasing PA levels of e.g., brown rice (Liang et al., 2008a) and legume seeds (Sattar, Durrani, Mahmood, Admad, \& Khan, 1989; Vijayakumari, Siddhuraju, Pugalenthi, \& Janardhanan, 1998), it also caused undesirable losses of water-soluble nutrients from e.g., soya beans (Bayram, Kaya, \& Oner, 2004), common beans (Barampama \& Simard, 1995), and other leguminous seeds (El-Adawy, Rahma, El-Bedawy, \& Sobihah, 
2000; Sattar et al., 1989). It is therefore important to balance both positive and negative aspects of soaking treatments.

Despite the importance of rice for human nutrition, the opportunities and limitations of wet processing for the improvement of mineral bioavailability in rice have not yet been clarified. Therefore the objectives of the present study were: (1) to explore the potential of soaking, endogenous phytase, exogenous phytase and combined treatments for the removal of PA from whole and ground rice products; and (2) to quantify the negative effects of nutritional relevance, particularly losses of dry matter and minerals.

\section{Materials and methods}

\subsection{Rice products}

Brown rice kernels, white rice kernels and rice bran (all of the same batch of variety Kenjian 90-31, harvested in 2005) were collected from Beijing Huateng Model Rice Mill Company, Beijing, China. Brown rice was obtained by de-husking rough rice; white rice was obtained by removing germs, testa and aleurone layers from brown rice; bran consisted of germs, testa and aleurone. Rice flours were prepared in a hammer-mill type grinder (HY-04B, Beijing Xinhuanya, China) and sieved through a $1 \mathrm{~mm}$ screen.

\subsection{Phytase}

Phytase was obtained from DSM (Delft, The Netherlands), with activity of $6000 \mathrm{U} \mathrm{g}^{-1}$, optimum temperature $55^{\circ} \mathrm{C}$, and optimum $\mathrm{pH}$ 2.5-5.5. The suggested dose based on application in animal feeds was $500 \mathrm{U} \mathrm{kg}^{-1}$ feed dry matter.

\subsection{Processing}

Raw materials were preheated, and soaked in various soaking media as outlined in Table 1. Preheating was included to allow differentiation between effects of exogenous (added) and endogenous phytase activity. No phytase activity was detected in preheated rice products (China National Standard Analysis Method, 2002). After soaking, kernels were separated from soaking media by decanting, and flours were separated by centrifugation at $5000 \mathrm{~g}$ during $15 \mathrm{~min}$ ). All treatments were carried out at least in duplicates. All solid residues were freeze-dried and kept at $4{ }^{\circ} \mathrm{C}$ prior to analysis.

\subsection{Phytic acid (PA)}

Contents of PA of all materials were analysed by spectrophotometric detection with ferric chloride $\left(\mathrm{FeCl}_{3}\right)$ and sulfosalicylic acid after extraction, separation on anion exchange resin according to the China National Standard Analysis Method as described previously (Liang et al., 2007).

\subsection{Phosphorus in soaking media}

The colorimetric method AOAC 995.11 (Horwitz, 2000) was used to determine phosphorus levels. Acid soluble phosphate forms a blue complex with sodium molybdate in the presence of ascorbic acid as reducing agent. The intensity of blue colour was measured spectrophotometrically at $823 \pm 1 \mathrm{~nm}$ (7200, Unico, Shanghai, China).

\subsection{Calcium, iron and zinc}

Minerals in solid residues were analysed using an inductively coupled plasma optical emission spectrometer (ICP-AES) (Optima 2000, Perkin-Elmer) after wet acid digestion with concentrated nitric acid $\left(\mathrm{HNO}_{3}, 65 \%\right)$ and perchloric acid $\left(\mathrm{HClO}_{4}, 60 \%\right)$ following the procedure of AOAC official method 975.03 (Horwitz, 2000).

\subsection{Data analysis}

Data were analysed using the SPSS package (Sony DADC, version 12.0.1). Significance was tested at a 5\% level using an unrelated $t$-test.

\section{Results}

The effects of rice products processing on phosphorus and phytic acid levels are presented in Figs. 1-3. In Table 2, the effects of processing on dry matter loss and $\mathrm{Ca}, \mathrm{Fe}$, and $\mathrm{Zn}$ levels are presented.

\subsection{White rice}

For white rice kernels, phytic acid (PA) started at relatively low levels and disappeared from the solids with a concomitant release of soluble phosphorus in the soaking medium (Fig. 1). No difference $(p>0.05)$ between unheated and preheated white rice was observed. Although the differences between treatments were small, phytase application led to significantly higher $(p<0.05)$ levels of phosphorus in the soaking media. For white rice flour, only treatments with phytase decreased PA to below detection level, and led to significantly higher $(p<0.05)$ levels of phosphorous in soaking media.

Acid soaking caused higher dry matter losses than other soaking media (Table 2). Calcium levels showed varying losses, which were bigger than for dry matter. Iron levels followed the same order of magnitude as calcium, with relatively higher losses from kernels

Table 1

Preheating and soaking treatments.

\begin{tabular}{|c|c|c|c|}
\hline Treatments & Methods & Code & Conditions \\
\hline \multirow[t]{2}{*}{ Preheating } & None & None & No preheating (control) \\
\hline & Dry preheating & DP & Heat in an ventilated hot air oven at $100^{\circ} \mathrm{C}$, kept for $30 \mathrm{~min}$, then cool to room temperature in sealed glass vessels \\
\hline \multirow[t]{3}{*}{ Soaking } & $\begin{array}{l}\text { Soaking medium: } \\
\text { Demineralised } \\
\text { water } \\
\text { (pH 5.95) }\end{array}$ & SDW & $\begin{array}{l}\text { Mix rice (kernels or flour) with medium at ratio } 1: 3(\mathrm{w} / \mathrm{v}) \text {, bran with medium at } 1: 5 \text { ratio }(\mathrm{w} / \mathrm{v}) \text {, then soak in a thermostat } \\
\text { incubator at } 10^{\circ} \mathrm{C} \text {, during } 172 \mathrm{~h} \text { (kernels) or } 24 \mathrm{~h} \text { (flour and bran) }\end{array}$ \\
\hline & $\begin{array}{l}\text { Soaking medium: } \\
\text { Acidic buffer } \\
\text { (HAc-NaAc, } 1 \mathrm{M} \text {, } \\
\text { pH 3.5) }\end{array}$ & SAB & $\begin{array}{l}\text { Mix rice (kernels or flour) with medium at ratio } 1: 3(\mathrm{w} / \mathrm{v}) \text {, bran with medium at } 1: 5 \text { ratio }(\mathrm{w} / \mathrm{v}) \text {, then soak in a thermostat } \\
\text { incubator at } 10^{\circ} \mathrm{C} \text {, during } 172 \mathrm{~h} \text { (kernels) or } 24 \mathrm{~h} \text { (flour and bran) }\end{array}$ \\
\hline & $\begin{array}{l}\text { Soaking medium: } \\
\text { Phytase solution } \\
\left(500 \mathrm{U} \mathrm{L}^{-1}\right)\end{array}$ & SPS & $\begin{array}{l}\text { Mix rice (kernels or flour) with medium at ratio } 1: 3(\mathrm{w} / \mathrm{v}) \text {, bran with medium at } 1: 5 \text { ratio }(\mathrm{w} / \mathrm{v}) \text {, adjust to } \mathrm{pH} 5.5 \mathrm{with} \mathrm{HAc} \\
\text { and } \mathrm{NaAc} \text {, then soak in a thermostat water bath at } 50 \pm 2{ }^{\circ} \mathrm{C} \text {, for } 30 \mathrm{~min}\end{array}$ \\
\hline
\end{tabular}




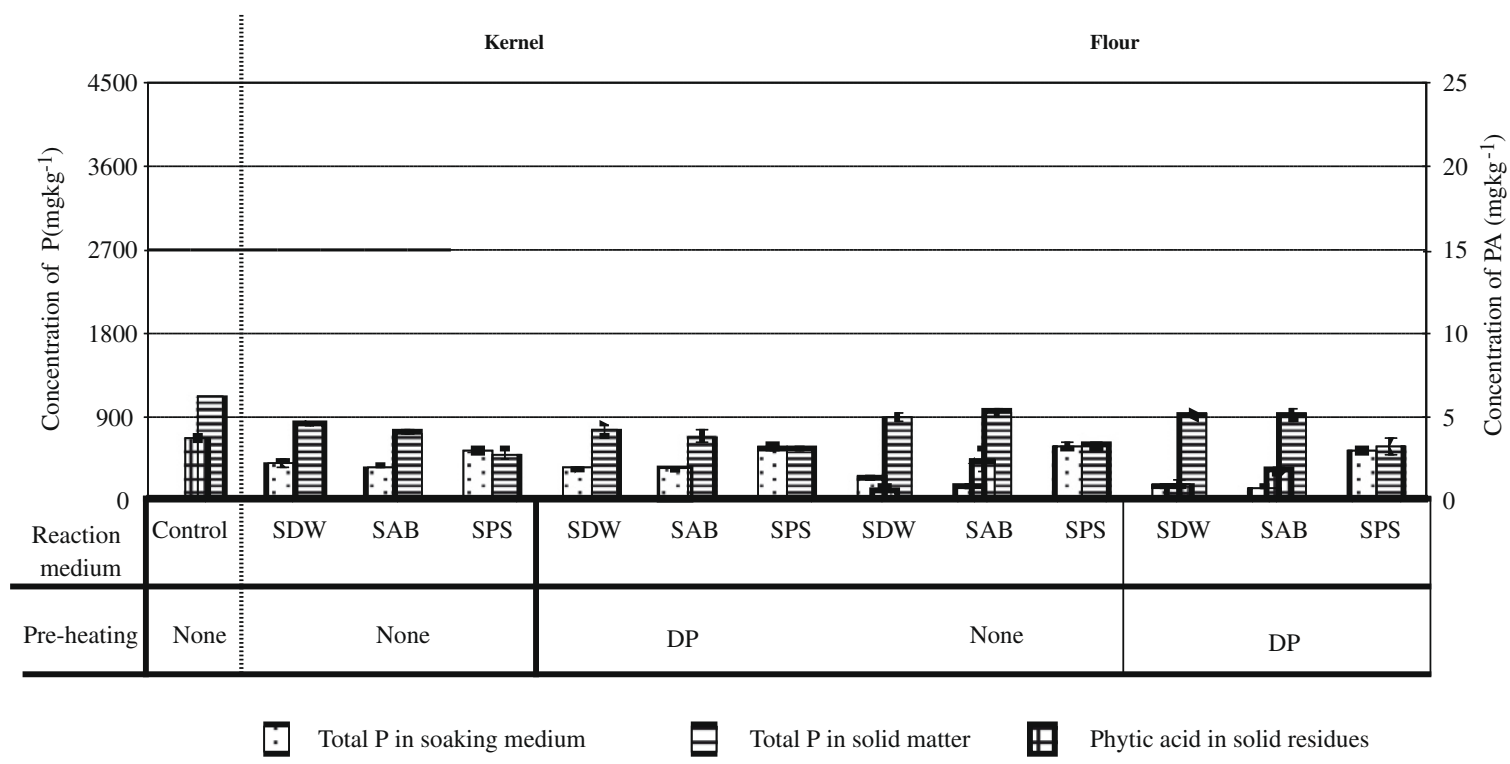

Fig. 1. Effect of preheating and soaking on phosphorus and phytic acid in white rice.

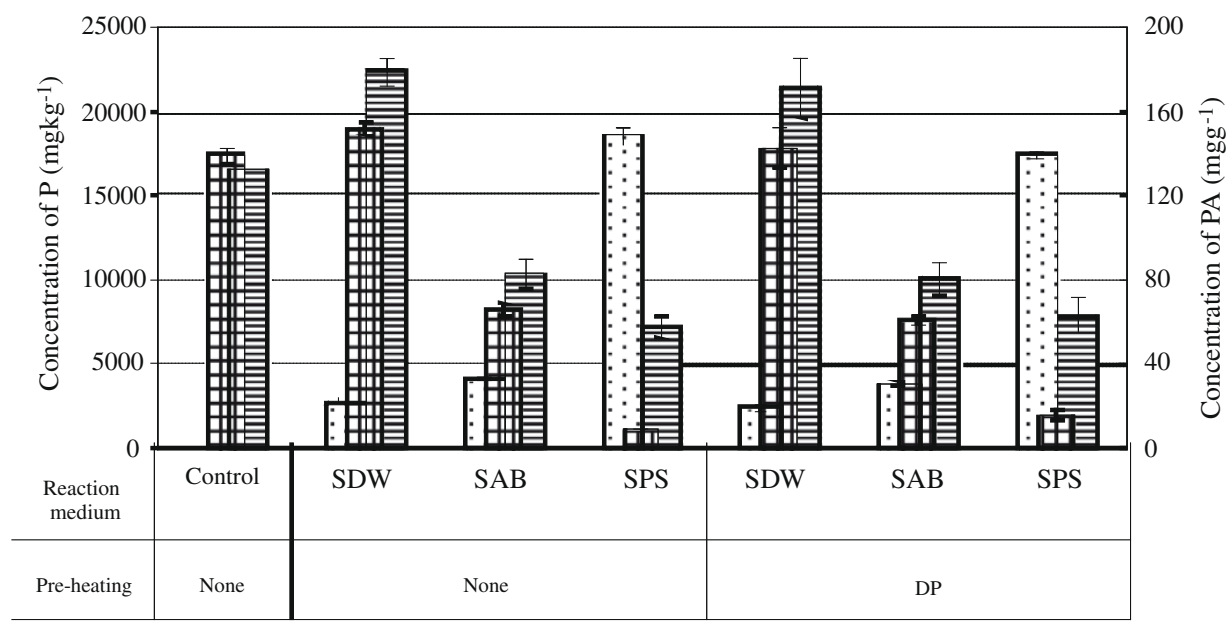

$\because$ Total $\mathrm{P}$ in soaking medium $\quad$ E Total $\mathrm{P}$ in solid matter $\quad$ Phytic acid in solid residues

Fig. 2. Effect of preheating and soaking on phosphorus and phytic acid in rice bran.

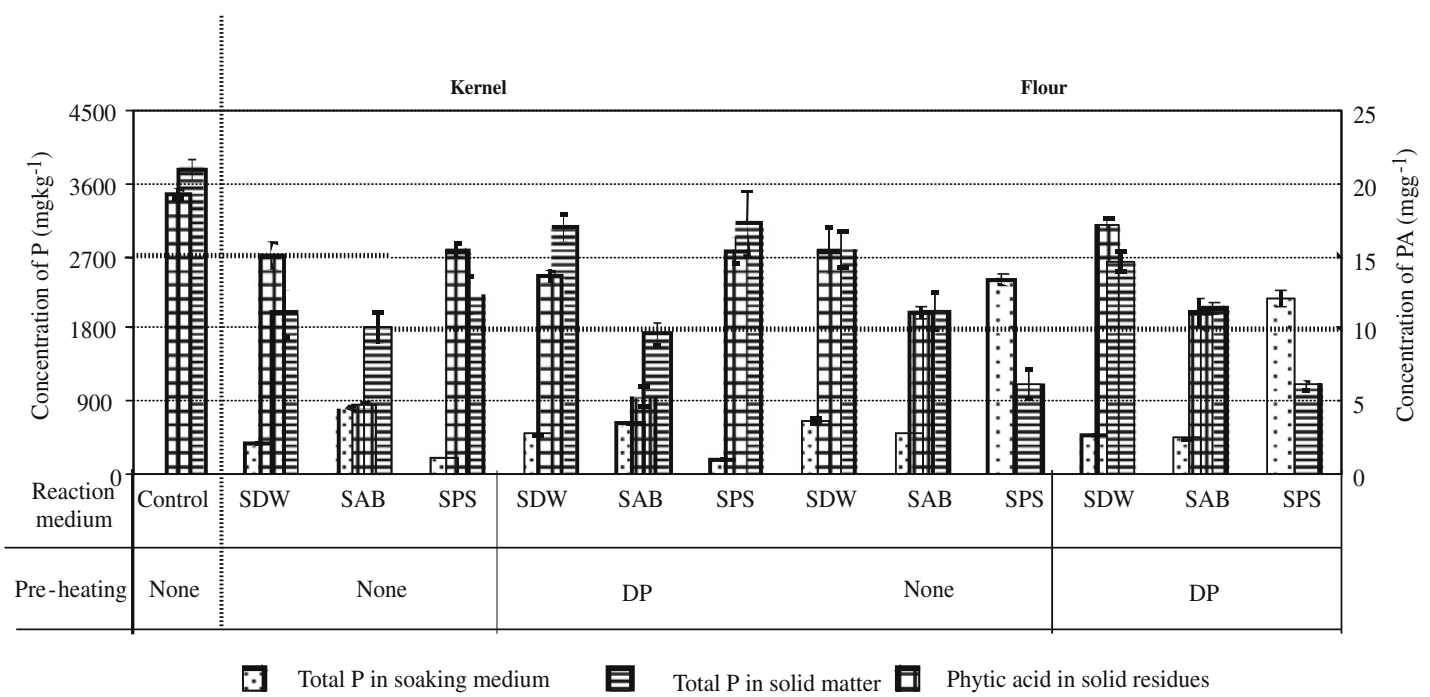

Fig. 3. Effect of preheating and soaking on phosphorus and phytic acid in brown rice. 
Table 2

Effect of preheating and soaking on dry matter, calcium, iron and zinc in rice products.

\begin{tabular}{|c|c|c|c|c|c|c|}
\hline Rice products & Preheating $^{\mathrm{a}}$ & Soaking $^{\mathrm{a}}$ & Dry matter loss ${ }^{\mathrm{b}}$ & $\mathrm{Ca}^{\mathrm{c}}$ & $\mathrm{Fe}^{\mathrm{c}}$ & $\mathrm{Zn}^{\mathrm{c}}$ \\
\hline \multicolumn{7}{|l|}{ White rice } \\
\hline Control & None & Control & 0 & $173 \pm 1$ & $28.7 \pm 3.8$ & $24.5 \pm 0.3$ \\
\hline \multirow[t]{6}{*}{ Kernel } & None & SDW & 8.6 & $127 \pm 5(-27)$ & $21.5 \pm 4.9(-25)$ & $24.5 \pm 2.6(-0)$ \\
\hline & & SAB & 15.1 & $86 \pm 17(-50)$ & $18.6 \pm 3.7(-35)$ & $22.8 \pm 3.6(-7)$ \\
\hline & & SPS & 2.0 & $153 \pm 16(-12)$ & $25.9 \pm 3.4(-10)$ & $42.1 \pm 9.1(+72)$ \\
\hline & DP & SDW & 13.0 & $123 \pm 23(-29)$ & $17.2 \pm 3.0(-40)$ & $23.0 \pm 3.6(-5)$ \\
\hline & & $\mathrm{SAB}$ & 19.7 & $118 \pm 10(-32)$ & $16.5 \pm 3.0(-43)$ & $24.2 \pm 3.3(-1)$ \\
\hline & & SPS & 3.9 & $73 \pm 1(-58)$ & $20.9 \pm 1.8(-27)$ & $40.8 \pm 7.2(+67)$ \\
\hline \multirow[t]{6}{*}{ Flour } & None & SDW & 6.2 & $136 \pm 24(-21)$ & $21.0 \pm 1.3(-27)$ & $27.8 \pm 12.6(+13)$ \\
\hline & & SAB & 16.1 & $106 \pm 18(-39)$ & $29.2 \pm 6.2(+2)$ & $15.3 \pm 2.9(-38)$ \\
\hline & & SPS & 4.9 & $64 \pm 14(-63)$ & $26.0 \pm 3.2(-9)$ & $40.0 \pm 1.6(+63)$ \\
\hline & DP & SDW & 6.5 & $149 \pm 22(-14)$ & $23.3 \pm 1.0(-19)$ & $33.3 \pm 7.0(+36)$ \\
\hline & & $\mathrm{SAB}$ & 13.1 & $114 \pm 4(-34)$ & $21.1 \pm 1.3(-26)$ & $30.2 \pm 7.0(+23)$ \\
\hline & & SPS & 9.6 & $127 \pm 28(-27)$ & $33.5 \pm 0.2(+17)$ & $28.1 \pm 2.2(+15)$ \\
\hline \multicolumn{7}{|l|}{ Rice bran } \\
\hline Control & None & Control & 0 & $617 \pm 26$ & $94.6 \pm 3.0$ & $57.5 \pm 1.1$ \\
\hline \multirow[t]{6}{*}{ Bran } & None & SDW & 7.4 & $628 \pm 44(+2)$ & $163.9 \pm 13.4(+73)$ & $19.3 \pm 1.7(-66)$ \\
\hline & & SAB & 15.1 & $493 \pm 20(-20)$ & $99.3 \pm 11.4(+5)$ & $15.4 \pm 2.4(-73)$ \\
\hline & & SPS & 20.2 & $318 \pm 22(-48)$ & $90.0 \pm 8.4(+5)$ & $21.0 \pm 0.4(-63)$ \\
\hline & DP & SDW & 28.7 & $671 \pm 50(+9)$ & $141.3 \pm 11.7(+49)$ & $22.3 \pm 3.0(-61)$ \\
\hline & & SAB & 29.8 & $524 \pm 18(-15)$ & $125.2 \pm 5.5(+32)$ & $16.1 \pm 1.5(-72)$ \\
\hline & & SPS & 19.4 & $334 \pm 8(-46)$ & $95.2 \pm 12.0(+1)$ & $21.9 \pm 3.1(-62)$ \\
\hline \multicolumn{7}{|l|}{ Brown rice } \\
\hline Control & None & Control & 0 & $284 \pm 18$ & $50.7 \pm 9.2$ & $34.0 \pm 0.4$ \\
\hline \multirow[t]{6}{*}{ Kernel } & None & SDW & 5.0 & $173 \pm 15(-39)$ & $34.7 \pm 9.4(-32)$ & $26.3 \pm 2.6(-23)$ \\
\hline & & $\mathrm{SAB}$ & 16.0 & $209 \pm 4(-26)$ & $28.0 \pm 10.6(-45)$ & $26.3 \pm 1.9(-23)$ \\
\hline & & SPS & 0.1 & $222 \pm 15(-22)$ & $26.6 \pm 4.1(-47)$ & $31.4 \pm 4.4(-8)$ \\
\hline & DP & SDW & 12.6 & $183 \pm 7(-36)$ & $27.6 \pm 4.1(-46)$ & $29.0 \pm 2.3(-15)$ \\
\hline & & $\mathrm{SAB}$ & 18.9 & $121 \pm 10(-57)$ & $20.2 \pm 4.1(-60)$ & $23.1 \pm 2.5(-32)$ \\
\hline & & SPS & 8.6 & $127 \pm 28(-55)$ & $33.5 \pm 0.2(-34)$ & $28.1 \pm 2.2(-17)$ \\
\hline \multirow[t]{6}{*}{ Flour } & None & SDW & 31.2 & $192 \pm 16(-32)$ & $35.0 \pm 5.1(-31)$ & $26.5 \pm 8.4(-22)$ \\
\hline & & SAB & 31.4 & $108 \pm 3(-62)$ & $31.4 \pm 4.5(-38)$ & $20.8 \pm 4.2(-39)$ \\
\hline & & SPS & 1.5 & $124 \pm 27(-56)$ & $30.9 \pm 3.3(-39)$ & $26.0 \pm 7.7(-24)$ \\
\hline & DP & SDW & 6.2 & $175 \pm 18(-38)$ & $28.2 \pm 5.8(-44)$ & $29.2 \pm 0.0(-14)$ \\
\hline & & $\mathrm{SAB}$ & 13.4 & $153 \pm 15(-46)$ & $32.8 \pm 4.4(-35)$ & $17.1 \pm 2.7(-50)$ \\
\hline & & SPS & 10.3 & $121 \pm 20(-57)$ & $27.5 \pm 2.0(-46)$ & $21.2 \pm 0.1(-38)$ \\
\hline
\end{tabular}

a For abbreviations, see Table 1.
b Dry matter loss: \% of control.

c $\mathrm{Ca}, \mathrm{Fe}$ and $\mathrm{Zn}: \mathrm{mg} \mathrm{kg}^{-1}$, data in brackets refers to \% change compared to control.

than from flour. Zinc followed another trend, with a number of apparent increases. In particular the phytase treatment results in higher zinc levels in the solid matter.

\subsection{Rice bran}

Levels of PA in rice bran were considerably higher than in white rice. No difference $(p>0.05)$ between unheated and preheated white rice was observed (Fig. 2). Acidic buffer reduced PA and total phosphorus by about $50 \%$ with a concomitant release of soluble phosphorus into the soaking medium, whilst soaking in demineralized water had no such effect. In contrast, mild increases of especially total $\mathrm{P}$ in soaking medium and in solid matter were observed which are most likely related to leaching into the soaking medium, and apparent increase due to shifts in solid matter composition, respectively. The application of phytase was even more effective; considering the very high initial phytate level a higher phytase activity or longer exposure time might have been required to obtain a complete PA removal (Egli, Davidsson, Juillerat, Barclay, \& Hurrell, 2002).

The dry matter losses (Table 2 ) were very high, up to almost $30 \%$. The mineral levels in bran, especially of calcium and iron, were more than four times higher than in white rice. Acidic buffer, and more so phytase soaking resulted in strong migration of calcium and zinc into the soaking medium. Zinc levels were about twice higher than in white and brown rice, and suffered more than calcium, from leaching into the soaking media.

\subsection{Brown rice}

The results obtained with brown rice to a large extent paralleled those of rice bran. An interesting contrast was observed between the kernels and flour (Fig. 3). In kernels, soaking in water and acidic buffer gave similar results as in bran, i.e. water was not effective whereas acidic buffer extracts phytate phosphorus with release of soluble phosphorus into the medium. Phytase had no significant effect $(p>0.05)$. In contrast, in brown rice flour, phytase was highly effective resulting in removal of PA to below detection level.

The dry matter losses (Table 2) from whole kernels were of the same order as from white rice kernels. From brown rice flour, much more dry matter was lost by soaking. Calcium levels in brown rice were higher than in white rice, but the relative losses were similar as a result of soaking. The same can be observed for iron and zinc.

\section{Discussion}

Preheating and soaking conditions had diverse effects on PA and minerals in the tested rice products. In order to distinguish influences of endogenous and added phytase on PA degradation, endogenous phytase was inactivated by preheating. The effect of dry preheating was however, negligible, indicating that under the experimental conditions, rice endogenous phytase does not have a significant effect $(p>0.05)$ on PA. Phytase addition treatments resulted in significant $(p<0.05)$ PA degradation, with concomitant release of phosphate into the soaking medium; the release of phos- 
phate as a result of phytase treatment was also observed in feed (Wu, Ravindran, Pierce, \& Hendriks, 2004).

Soaking in water and acidic buffer also resulted in lower PA levels. In principle, two factors could be responsible for the impact of soaking, i.e. endogenous phytase activity and diffusion of PA into the soaking medium. Whilst endogenous phytase was functional in rice-based products (Perlas \& Gibson, 2002) and mungbean (Sattar et al., 1989), it was of no relevance in our study as mentioned earlier. Diffusion of PA was reportedly influenced by the nature of the phytate, which may be in the form of salts with different minerals, such as potassium, calcium or magnesium, and the $\mathrm{pH}$ of the medium (Mahgoub \& Elhag, 1998). Soaking in distilled water was more effective to remove PA from pulses than in solution of sodium bicarbonate $(0.02 \%, \mathrm{w} / \mathrm{v})$ (Vijayakumari et al., 1998$)$. We observed that soaking in acidic buffer was more effective to remove PA from brown rice and rice bran than in demineralised water, presumably because of the higher solubility of phytates in acidic conditions.

We previously reported (Liang et al., 2008a) that levels of minerals in rice products can be ranked in decreasing order as follows: rice bran > brown rice > white rice; this is related to their distribution in the rice kernels and the effect of processing. Investigations elsewhere reported losses of minerals from rice products during soaking to be mainly caused by diffusion into the soaking medium (Barampama \& Simard, 1995). Increases of mineral concentration occurred in selected instances, which could be attributed to a proportionately greater loss of dry matter. Quantities of minerals lost are influenced by the soaking conditions (e.g., pH, temperature) and also by complexation of minerals with other components, such as PA, fibre and polyphenols. Only those minerals released from such complexes would be soluble in the soaking medium (Lestienne et al., 2005b). We observed that soaking caused a significant decrease (12-63\%) of calcium in almost all rice products. From rice bran, absolute losses of calcium ranging from $46 \%$ to $48 \%$ (phytase treatment) and from $15 \%$ to $20 \%$ (acidic buffer soak) were observed whilst calcium concentrations on dry matter basis apparently increased slightly (2-9\%); we consider this to be a consequence of the considerable dry matter losses (7-30\%) that took place simultaneously. We suggest that phytase-catalysed release of calcium from insoluble complexes, and acidic $\mathrm{pH}$ favouring solubility, are the main causes for this mineral extraction. An increase of zinc in white rice dry matter is explained by the loss of water-soluble matter from the surface and retention of zinc which is distributed in the endosperm; an increase of iron in rice bran dry matter is explained by its retention by bonding with phytate and the loss of soluble endosperm remainders which result in a loss of zinc. Further work will be required to establish a material balance for the minerals and other components during soaking of rice components. Regardless of other applications, acidic or phytase soaking of rice bran may be a profitable way to recover minerals for food or feed uses.

The results suggested that acid soaking of white rice was adequate to dephytinize intact kernels. For bran, dephytinizing with phytase caused a majority of minerals to be dissolved in liquid medium, which could be applied profitably as a natural mineral enrichment for food or feed use. The data on whole brown rice vs. milled rice give a very clear illustration of the function of the testa and aleurone layers as a barrier to influx of e.g., phytase, and diffusive loss of matter. It has been reported that the presence of bran, which retards water penetration and therefore the leaching of solids (Bello, Tolaba, \& Suarez, 2004), limits the passage of phytate and phytase (Lestienne et al., 2005c). The effect of the bran layer is also the main reason for the lower mass loss of whole brown rice soaked in demineralised water than in acidic buffer; this difference might be caused by a modification of the outermost layer of bran in acidic conditions, so that increased losses of solid mass would occur. A similar situation was observed in dehulled beans (Aminigo \& Metzger, 2005; Bayram et al., 2004).

\section{Conclusions}

White rice, rice bran and brown rice underwent different patterns of losses of dry mass, minerals and phytic acid, when soaked with demineralized water, acidic buffer and phytase solutions after preheating. White rice contained $4 \mathrm{mg} \mathrm{g}^{-1}$ phytic acid which was removed by all treatments to below detection level. Dry matter losses due to soaking ranged from 2-20\% with the highest losses observed after soaking in acidic buffer. Whereas relatively high losses of calcium (12-63\%) and iron (9-43\%) were recorded, zinc losses were lower (0-38\%). Bran contained $140 \mathrm{mg} \mathrm{g}^{-1}$ phytic acid which was removed best $(-92 \%)$ by phytase treatment, followed by soaking in acidic buffer $(-50 \%)$. Dry matter losses from bran due to soaking were highest (7-30\%) of all rice products. Bran contains the highest levels of calcium $\left(671 \mathrm{mg} \mathrm{g}^{-1}\right)$, iron $\left(95 \mathrm{mg} \mathrm{g}^{-1}\right)$ and zinc ( $57 \mathrm{mg} \mathrm{g}^{-1}$ ), and phytase treatment resulted in dissolution of $50-70 \%$ in the soaking medium. Brown rice contained $20 \mathrm{mg} \mathrm{g}^{-1}$ phytic acid which was removed best from kernels (75\% of initial) by soaking in acidic buffer, but in flour by phytase application to below detection levels. Dry matter losses due to soaking ranged from $0.1 \%$ to $31 \%$ with highest losses observed after soaking in acidic buffer. Brown rice contains about two-fold higher levels of calcium, iron and zinc than white rice. However, losses due to soaking were similar as in white rice, for calcium (22$62 \%)$, iron (31-60\%), and zinc (8-50\%).

Phytase application is an effective method to rapidly remove phytic acid whilst preserving relatively more dry matter and minerals than other soaking approaches in rice products.

\section{Acknowledgement}

Financial support was provided by Wageningen University through the North-South Interdisciplinary Research and Education Fund (INREF). We gratefully acknowledge Dr. Cheng Suhong of Beijing Huateng Model Rice Mill Company (Beijing, China) who provided brown rice, white rice and rice bran. We also gratefully acknowledge the assistance of Lin Li and Jin Ying for mineral analysis.

\section{References}

Aminigo, E. R., \& Metzger, L. E. (2005). Pretreatment of African yam bean (Sphenostylis stenocarpa): Effect of soaking and blanching on the quality of African yam bean seed. Plant Foods for Human Nutrition, 60(4), 165-171.

Barampama, Z., \& Simard, R. E. (1995). Effects of soaking, cooking and fermentation on composition, in vitro starch digestibility and nutritive value of common beans. Plant Foods for Human Nutrition, 48(4), 349-365.

Bayram, M., Kaya, A., \& Oner, M. D. (2004). Changes in properties of soaking water during production of soy-bulgur. Journal of Food Engineering, 61(2), 221-230.

Bello, M., Tolaba, M. P., \& Suarez, C. (2004). Factors affecting water uptake of rice grain during soaking. Lebensmittel-Wissenschaft - und Technologie, 37(8), 811-816.

China National Standard Analysis Method (2002). Analysis of phytase activity in feed (GB/T 18634-2002)

Egli, I., Davidsson, L., Juillerat, M. A., Barclay, D., \& Hurrell, R. F. (2002). The influence of soaking and germination on the phytase activity and phytic acid content of grains and seeds potentially useful for complementary feeding. Journal of Food Science, 67(9), 3484-3488.

El-Adawy, T. A., Rahma, E. E., El-Bedawy, A. A., \& Sobihah, T. Y. (2000). Effect of soaking process on nutritional quality and protein solubility of some legume seeds. Die Nahrung, 44(5), 339-343.

FAO (2006). FAOstat http://faostat.fao.org/ (last accessed November 2006).

Horwitz, W. (2000). Official Methods of Analysis of AOAC International. Maryland: AOAC International: Association of Official Analytical Chemists, AOAC (Washington, D.C.).

Lestienne, I., Besançon, P., Caporiccio, B., Lullien-Pellerin, V., \& Trèche, S. (2005a). Iron and zinc in vitro availability in pearl millet flours (Pennisetum glaucum) with varying phytate, tannin, and fibre contents. Journal of Agricultural and Food Chemistry, 53(8), 3240-3247. 
794

J. Ling et al./Food Chemistry 115 (2009) 789-794

Lestienne, I., Caporiccio, B., Besançon, P., Rochette, I., \& Trèche, S. (2005b). Relative contribution of phytates, fibres, and tannins to low iron and zinc in vito solubility in pearl millet (Pennisetum glaucum) flour and grain fractions. Journal of Agricultural and Food Chemistry, 53(21), 8342-8348.

Lestienne, I., Icard-Vernière, C., Mouquet, C., Pica, C., \& Trèche, S. (2005c). Effects of soaking whole cereal and legume seeds on iron, zinc and phytate contents. Food Chemistry, 89(3), 421-425.

Lestienne, I., Mouquet-Rivier, C., Icard-Vernière, C., Rochette, I., \& Trèche, S. (2005d). The effects of soaking of whole, dehulled and ground millet and soybean seeds on phytate degradation and $\mathrm{Phy} / \mathrm{Fe}$ and $\mathrm{Phy} / \mathrm{Zn}$ molar ratios. International Journal of Food Science and Technology, 40(4), 391-399.

Ling, J., Han, B.-Z., Han, L., Neut, M. J. R., \& Homer, R. J. (2007). Iron, zinc, and phytic acid content of selected rice varieties from China. Journal of the Science of Food and Agriculture, 87, 504-510.

Liang, J., Han, B.-Z., Neut, M. J. R., \& Homer, R. J. (2008a). Effects of soaking, germination and fermentation on physic acid, total and in vito soluble zinc in brown rice. Food Chemistry, 110, 821-828.

kiang, J., Li, Z., Tsuji, K., Nakano, K., Neut, M. J. R., \& Homer, R. J. (2008b). Milling characteristics and distribution of physic acid and zinc in long-, medium- and short-grain rice. Journal of Cereal Science, 48, 83-91.

Lu, Z. H., Li, L. T., Min, W. H., Wang, F., \& Tatsumi, E. (2005). The effect of natural fermentation on the physical properties of rice flour and the rheological characteristics of rice noodles. International Journal of Food Science and Technology, 40, 985-992.

Ma, G. (2007). Iron and Zinc Deficiencies in China: Existing Problems and Possible Solutions vol. PhD. Thesis. Wageningen: Wageningen University.

Mahgoub, S. E. O., \& Elhag, S. A. (1998). Effect of milling, soaking, malting, heattreatment and fermentation on phytate level of four Sudanese sorghum cultivars. Food Chemistry, 61, 77-80.

Perlas, L. A., \& Gibson, R. S. (2002). Use of soaking to enhance the bioavailability of iron and zinc from rice-based complementary foods used in the Philippines. Journal of the Science of Food and Agriculture, 82(10), 1115-1121.

Tatar, A., Durrani, S. K., Mahmood, F., Admad, A., \& Khan, I. (1989). Effect of soaking and germination temperatures on selected nutrients and antinutrients of mungbean. Food Chemistry, 34(2), 111-120.

Vijayakumari, K. K., Siddhuraju, P., Pugalenthi, M., \& Janardhanan, K. K. (1998). Effect of soaking and heat processing on the levels of antinutrients and digestible proteins in seeds of Vina aconitifolia and Vina sinensis. Food Chemistry, 63(2), 259-264.

Wang, L. (2005). 2002 China Nutrition and Health Survey. (Overall Report): People's Medical Publishing House.

Wu, Y. B., Ravindran, V., Pierce, J., \& Hendriks, W. H. (2004). Influence of three phytase preparations in broiler diets based on wheat or corn: In vito measurements of nutrient release. International Journal of Poultry Science, 3(7), 450-455. 